\title{
¿QUÉ HACEMOS CON PEDRO CIPRÉS? APROXIMACIONES A UNA METODOLOGÍA DE LA VIDA COTIDIANA ${ }^{1}$
}

\author{
Pilar Gonzalbo Aizpuru \\ El Colegio de México
}

LO QUE LLAMAMOS METODOLOGÍA

\begin{abstract}
$\mathrm{G}$ algún momento de sus estudios, todos los futuros hisEtoriadores se preguntan si existe alguna regla aplicable a la investigación histórica en general, o adecuada a su tema en particular, que les permita transitar por camino seguro entre los archivos y las teorías. Esto es frecuente, sobre todo, entre los interesados en la historia cultural, que requiere más ideas y sensibilidades que fechas y nombres propios. Cuando estos jóvenes preguntan por la metodología, algunos maestros, más o menos presuntuosos, intentamos explicarla, como si nosotros mismos hubiéramos dispuesto de una teoría precisa, propia o tomada en préstamo y nos hubiéramos ajustado a ella, mediante
\end{abstract}

Fecha de recepción: 3 de septiembre de 2017

Fecha de aceptación: 15 de noviembre de 2017

\footnotetext{
${ }^{1}$ Agradezco, muy afectuosamente, a Leticia Pérez Puente y Enrique González los atinados comentarios y la gran ayuda que me han prestado en la localización y disponibilidad de fuentes esenciales para esta investigación.
} 
pasos medidos y contados. En ocasiones, hacemos trampa y alardeamos de que tuvimos algo como una iluminación que nos señaló lo que queríamos descubrir y nos encaminó hacia el archivo en el que encontraríamos respuestas a nuestras preguntas. Sin duda algo así puede suceder cuando se trata de confirmar datos concretos acerca de un acontecimiento, ya sea batalla, epidemia, biografía o cualquier decisión de carácter público y alcance reconocido; pero no es lo mismo cuando nos referimos a hechos sociales que podemos identificar como "no acontecimientos”. Que esta ruta haya sido exitosa para algunos trabajos en particular es algo encomiable, pero no transmisible. No es remoto que una pregunta concreta, algún tema apenas vislumbrado, termine por convertirse en una hipótesis bien fundamentada e inmediatamente comprobada entre legajos y mamotretos, pero sería deshonesto recomendar como método de trabajo la espera de las musas que nos traigan la deseada inspiración. Algo diferente, y por supuesto esencial, es tener claro el interés por un enfoque determinado, una época precisa o un posible problema identificable. Junto a esa intención vagamente diseñada, el trabajo artesanal, la modestia para enfrentar nuestras ignorancias y el sano equilibrio entre imaginación e información, pueden lograr lo que en vano esperamos de la magia.

Estoy lejos de rechazar las intuiciones y las afinidades con determinados tiempos, personas y experiencias, ya que la atracción de una época o un tema pueden influir favorablemente en su desarrollo, pero no sustituyen al análisis cuidadoso de las fuentes y las ideas aplicables. Mi opinión se inclina hacia las ventajas de asumir la propia responsabilidad en un trabajo que requiere reflexión, perseverancia y honestidad. El estudio de las generalidades propias de la vida en una época, el acercamiento a creaciones literarias, logros del pensamiento, manifestaciones artísticas y modestas listas de consumo, descripciones o imágenes de viviendas, modas y costumbres, es lo que puede acercarnos a atisbar creencias y representaciones propias de cualquier 
sociedad, y podemos llegar a ellas a partir de un sencillo documento, un relato o un objeto, el testimonio en apariencia irrelevante, pero en realidad revelador de una faceta de ese mundo al que nos aproximamos. No pretendo construir fortalezas a partir de cenizas ni dejar volar la fantasía sobre huellas borrosas en las que es aventurado confiar. La fantasía impulsa a crear lo inexistente, mientras que la imaginación trata de encontrar sentido en lo cercano, real, visible y aparente, a partir de experiencias y representaciones previas, necesarias para conocer el contexto de cualquier objeto de estudio. Tengo muy presente esta diferencia y por eso hablo de lo que se ha designado como conocimientos o ideas a priori, sin las cuales un legajo sólo es un paquete de documentos, un viejo edificio sólo es un desorden de piedras deterioradas y una inscripción es un puzle de letras y números. Sin la previa reserva de conocimientos, es muy poco lo que los documentos nos transmiten. La entrada en cualquier taller o laboratorio sin disponer de la instrucción precisa puede desembocar en el ridículo o en un desastre, y los historiadores somos modestos artesanos que en nuestro taller utilizamos como materiales los preciosos testimonios de antaño. Pero los documentos permanecen silenciosos ante quien no sabe leerlos; cada época y cada sector de la sociedad, cada profesión y cada actividad específica cuenta con sus propios códigos de interpretación, del mismo modo que los libros sagrados no decían nada a los señores indígenas a quienes los conquistadores españoles les aseguraban que ahí estaba la palabra de Dios.

Mi experiencia me permite ser optimista en cuanto a los hallazgos, a la vez que me ha enseñado modestia en cuanto a las expectativas. En un tiempo ya bastante remoto, con una idea muy general y bastante vaga de lo que buscaba, visité archivos y fui encontrando datos, comentarios, incluso reflexiones sobre épocas, personas y acontecimientos. Mis intereses fueron la educación, la familia, la situación de las mujeres en el pasado y la vida cotidiana. Quizá parezcan demasiados temas y habrá quien 
no los considere enlazados, pero no es difícil aceptar que nuestro comportamiento a lo largo de la vida, lo que le da sentido, que es precisamente lo cotidiano, depende de lo que aprendemos, lo que nos enseñaron en la escuela y en el hogar; sin olvidar que las mujeres son protagonistas en estos espacios. Así que, entre aulas y lecturas, amistades y relaciones familiares, fui encontrando los elementos que dan forma a las rutinas del acontecer diario, tanto en la vida privada como en comunidad. Cuando creía encontrar respuestas, podía suceder que estuvieran semiescondidas en voluminosos expedientes, pero, en ocasiones, lo que me atraía era un fragmento, una página de una carta, un juicio o una crónica en donde se percibía la trascendencia de un hecho social.

\section{LOS TESTIMONIOS Y EL HECHO SOCIAL}

En el ramo Universidad del Archivo General de la Nación de México, identifiqué un periodo en el que abundan los expedientes relativos a la legitimidad y limpios orígenes de aspirantes a ingreso a alguna facultad. Estos expedientes son relativamente frecuentes desde comienzos del siglo XvIII, cuando se cuidaba la aplicación de los estatutos de la Real Universidad, ya aprobados y publicados, pero con los que todavía no estaban muy familiarizados los funcionarios ni los estudiantes. ${ }^{2}$ En la segunda mitad del siglo fueron más numerosos los problemas causantes de la documentación relativa al nacimiento y los progenitores de los jóvenes que no podían exhibir su acta de bautismo como hijo legítimo de padres españoles o indios. Menos de $20 \%$ de los casos se refiere a lo que se consideraba la "mancha" de

${ }^{2}$ La organización de los estudiantes en la Real Universidad se menciona en Pavón Romero, "La organización escolar" y "La población universitaria”. En cuanto a la evolución en el siglo XVII, RodríGuEz-SALA, Alumnos, bachilleres $y$ licenciados. 
ancestros africanos que alguna vez pudieron ser esclavos. ${ }^{3} \mathrm{El}$ resto se refiere a la exigencia de acreditar el nacimiento de padres unidos en legítimo matrimonio.

Cada uno de esos expedientes (en total he visto poco más de cincuenta) podía reflejar una historia familiar, pero ninguno llegó a generar un verdadero escándalo que atrajera la atención de autoridades ajenas al mundo académico. Eran, eso sí, ejemplos de un comportamiento alejado de los estereotipos que consideraban la Universidad como coto exclusivo de españoles más o menos acomodados, y que bien podrían interpretarse como escenas del drama cotidiano. Esto es lo que sentí cuando, en el año $1989,{ }^{4}$ encontré la carta de una sola página en que el virrey Marqués de Cerralvo, en 1634, respaldaba la decisión propuesta por el rector de la Real y Pontificia Universidad de México en un problema suscitado por los estudiantes de la facultad de Medicina. Ni remotamente se refiere el documento a algo que pueda considerarse un acontecimiento, $\mathrm{y}$, sin embargo, tuvo trascendencia; tampoco detalla las condiciones del contexto, que sólo puede intuirse, y en ningún momento se da la palabra al verdadero protagonista: el mulato Pedro Ciprés. Con el documento en mis manos, y el ambiente barroco universitario de la ciudad de México en el siglo xviı como escenario, pude formular preguntas que ahora pretendo responder, para mostrar, y mostrarme a mí misma, el incierto camino por el que transitamos cuando pretendemos dar el paso del documento a las teorías o de las presunciones a las realidades.

\footnotetext{
${ }^{3}$ Los procedimientos relativos a dudas sobre legitimidad y limpieza de sangre para ingreso en facultades se conservan, en gran parte, en el AGN, Universidad, vol. 81, ff. 317 a 685v. Se encuentran someras referencias a algunos de ellos en Gonzalbo Aizpuru, Historia de la educación, pp. 115-116.

${ }^{4}$ Inserté un comentario sobre el caso particular de Pedro Ciprés en mi libro Historia de la educación en la época colonial. La educación de los criollos (1990), pp. 115-116. Años más tarde lo retomaron Menegus y Aguirre en Los indios (2006), p. 61.
} 
¿Cómo penetrar en los contenidos implícitos en cualquier documento y precisamente en el que tengo ante mí? ¿Cómo interpretar los símbolos representados en expresiones que se refieren a creencias, prejuicios, valores y mentalidades compartidas por los protagonistas? ¿Hasta dónde podrá llevarme la lectura atenta y la "descripción densa" ${ }^{5}$ de un mensaje escrito hace poco menos de cuatrocientos años? En el documento, en cualquier documento, se proyectan espacios y tiempos, actores, situaciones, dudas o certezas, intenciones explícitas o, con frecuencia, ocultas, y formas de expresión sometidas a códigos que debo conocer. Las preguntas son numerosas porque cada categoría admite una variedad de predicables que pueden aplicarse. ${ }^{6}$ En este caso, más que pregunta, mi inquietud se relaciona con los símbolos representativos de una sociedad de la que conocemos algunos aspectos, pero ignoramos muchos más. La época y el lugar pueden decirnos muchas cosas: ¿qué había sucedido en años anteriores?, ¿y en el tiempo en que se produjo el incidente?, ¿qué características tenía la capital del virreinato de la Nueva España? Los personajes mencionados sugieren nuevas posibilidades de comprensión del texto. ¿Cuál era la relación de respeto o dependencia entre remitentes y receptores de la carta? ¿Qué trascendencia tenía la calidad de mulato del causante del problema? Los sentimientos expresados quizá encubren más de lo que dicen en cuanto a las motivaciones de los denunciantes. ¿Qué pudo motivar que la crisis se suscitase precisamente en ese momento y no unos años antes? ¿Qué ofrecía la carrera de Medicina y cuál era su reconocimiento en el mundo académico y en la vida cotidiana? La opinión del rector y la sentencia del

${ }^{5}$ No dejo de tener presente la recomendación del antropólogo Clifford Geertz, que bien puede aplicarse al estudio de los archivos, en La interpretación de las culturas, capítulo I.

${ }^{6}$ Me remito a la vieja y desacreditada lógica aristotélica, que, pese a su vejez, me permite articular la relación entre los distintos caracteres y niveles capaces de definir el relato. 
virrey completan ese diálogo que quedó abierto en las primeras líneas. El primer paso, sin duda, es la lectura del documento.

\section{EL DOCUMENTO Y SU IMPORTANCIA}

Una hoja única, en el ramo Universidad del Archivo General de la Nación de México, no parece ser muy prometedora en cuanto a la información proporcionada o la trascendencia de su contenido. ${ }^{7}$ Salvo que no es una carta cualquiera sino dirigida por un virrey al rector de la Universidad. En letra apretada, pero fácilmente legible, con datos precisos y texto escueto, la carta plantea la protesta de un grupo de bachilleres por la presencia en la facultad de Medicina de un estudiante mulato.

El motivo tampoco parece sorprendente. He estudiado expedientes mucho más extensos y complejos relativos a la incomodidad de algunos universitarios por la presencia de compañeros o colegas a quienes consideraban de inferior calidad. En este caso, sin extensos alegatos ni despliegue de anécdotas o antecedentes, con una ambigua acusación, se llega, en pocas palabras, a la petición, acompañada de las recomendaciones del rector y de la resolución definitiva del virrey. Su misma sencillez, el lenguaje llano y las reflexiones compartidas por ambas autoridades hacen atractivo el texto, alejado de las rebuscadas consideraciones propias de leguleyos y funcionarios capaces de ocultar turbios intereses. Ya fuera por honestidad de ambos o porque no estaban en juego intereses políticos o económicos, la decisión fue, simplemente, la que imponía la legislación vigente. Algo especial y que, por lo tanto, reviste particular interés, es la fecha.

Fecho en Mexico a veinte uno del mes de agosto de 1634 años.

7 AGN, Universidad, vol. 40, ff. 172-172v. 
Faltaba más de medio siglo para que la cuestión de las calidades se convirtiera en motivo de preocupación. Todavía no había llegado a la Nueva España don Juan de Palafox y Mendoza, el visitador, obispo y virrey interino, cuyos estatutos, en vigor desde el último tercio del siglo, regirían los últimos años de la Universidad y en los cuales se mencionaría la exclusión de determinados grupos. En 1634, no se trataba, por tanto, de cumplir o hacer cumplir una ley por entonces inexistente, sino de considerar una cuestión, quizá latente, de representaciones, percepciones, prejuicios compartidos y miedos colectivos. Parece ser una de las primeras expresiones de alarma por parte de los criollos, cuando ya no era discutible si los miembros de las castas tendrían capacidad para desempeñar las mismas profesiones y oficios en que se ocupaban los españoles, sino que, siendo innegables sus aptitudes, se especulaba sobre la posibilidad de evitar que compitieran en cualquier terreno. Pero la fecha nos dice algo más porque, pocos meses antes de su partida, cuando ya el virrey había solicitado su relevo, parece lógico pensar que, antes que buscar nuevos motivos de agravios, preferiría complacer a los vecinos más influyentes proponiendo una solución que podría ser ampliamente aceptada. Desde la perspectiva de la vida universitaria, el primer tercio del siglo xvir era una época que iniciaba cambios, cuando aumentaba el número de estudiantes en Teología y Cánones y comenzaban a graduarse los primeros médicos que habían cursado sus estudios en la Nueva España. En pleno crecimiento de la Universidad y de la ciudad, la gran inundación significó una violenta ruptura, una crisis de proyectos económicos y culturales y, sin duda alguna, la frustración de quienes habían confiado en el brillante porvenir que prometía la antes floreciente capital. Eran tiempos en que la población indígena iniciaba su recuperación, la sociedad criolla accedía a cargos capitulares en las catedrales, los hacendados alardeaban de alcurnia, y los empresarios y negociantes se enriquecían con la minería y el comercio. En su aparente inmovilidad, paz y 
armonía, en el virreinato se gestaban ambiciones y resentimientos, aspiraciones de libertad y expectativas de igualdad.

A favor del buen juicio del virrey, puede apuntarse que su respuesta apenas ocupa cuatro o cinco líneas, mientras el desarrollo del problema se despliega en el resto del documento. Sin duda instruido por el marqués, y porque ése era el formato que solicitaba en los casos en que se demandaba su decisión como árbitro de cuestiones opinables, el secretario o escribiente a cargo de preparar el texto sintetizó los motivos de la demanda y la objeción del rector de la Universidad para satisfacer a los quejosos. Cerralvo pudo entender cabalmente el problema, no sólo desde la mirada autoritaria propia del vicepatrono de la Universidad, en nombre del monarca, sino porque ya había revisado los textos legales que sus asesores prepararon años atrás para cumplimentar la orden de elaborar nuevos estatutos.

El documento es más bien sobrio, aunque no falta la mención de los títulos honoríficos que ostentaba el virrey, quien no pretende dictar solemnemente una sentencia sino expresar lo que más bien parece una opinión, en la que incluso se permite la ambigüedad de aceptar lo legislado, aunque no esté de acuerdo con ello, y anunciar la intención de cambiar algo que pasó por sus manos y no cambió.

EL TEXTO HABLA

Don Rodrigo Pacheco Osorio Marqués de Cerralbo del Consejo de Guerra Virrey Lugartheniente del Rey Nuestro Señor Gobernador y capitán general de esta Nueva España y presidente de la Audiencia $y$ chancilleria real que en ella reside $=$

El marqués había llegado a ocupar su cargo en momentos de crisis, tras los graves enfrentamientos entre su antecesor, Marqués de Gelves, y la Audiencia y el Ayuntamiento, las fuertes instituciones de gobierno local. No era fácil restañar las heridas 
tras la actuación de un gobernante intransigente y severo, austero consigo mismo y decidido a terminar con la corrupción imperante en todos los niveles de gobierno. La violenta salida de Gelves dejaba insatisfechos a todos los participantes en los enfrentamientos provocados por el depuesto virrey. Desde su llegada, don Rodrigo Pacheco hizo gala de una actitud más conciliadora y tolerante, lo que le permitió mantenerse en el gobierno durante diez años, claudicar en algunas de las medidas que más habían inquietado a los criollos, conservar el frágil equilibrio de fuerza con un arzobispo celoso de sus privilegios y mantener la dignidad y el prestigio de su investidura. Por sus propias palabras sabemos que había recibido instrucciones directas del monarca Felipe IV quien, entre otros asuntos, le había encargado la redacción de nuevos estatutos para la Real y Pontificia Universidad de México. ${ }^{8}$ Poco después de su llegada (1624) ordenó la revisión de los anteriores reglamentos (los estatutos de Salamanca de 1529, que provisionalmente se aplicaron, y las reformas posteriores de los mismos, las constituciones del oidor Agustín Farfán y del arzobispo Pedro Moya de Contreras, que nunca tuvieron reconocimiento oficial) y la elaboración de un nuevo texto. Con la redacción provisional concluida, lo sometió a la aprobación de autoridades universitarias y, al parecer, ahí quedó bloqueado largo tiempo, por lo cual no se avanzó en el procedimiento por el que pudo haber sido enviado a la corte para su aceptación.

Las luchas por el poder en la Universidad, entre clérigos y laicos, eclesiásticos seculares y regulares, fueron uno más de los problemas que tuvo que afrontar, pero de ninguna manera el único ni el más importante. Durante su gobierno, la ciudad de México había padecido la peor inundación de la que se tuviera noticia. Las aguas torrenciales que anegaron la ciudad en 1629

8 “Estudio introductorio" de Enrique González en Proyecto de estatutos, pp. 26-30. 
tardaron casi dos años en retirarse por completo y provocaron el deterioro, y en ocasiones el derrumbe o destrucción total, de edificios de adobe, la ruina de algunos comercios y talleres y la emigración de quienes disponían de bienes suficientes para establecerse en otras ciudades. La recaudación de bienes propios de la capital se vio igualmente afectada. Por otra parte, la precaria armonía que el virrey había logrado recuperar, tras los motines de 1624 , se vio amenazada una y otra vez por los desacuerdos con el arzobispo Francisco Manso de Zúñiga. No es arriesgado suponer que, en esas circunstancias, cuando ya había solicitado que lo relevasen del cargo y estaba próximo a regresar a España, Cerralvo procuraría suavizar tensiones y evitar enfrentamientos.

En cuanto al gobierno universitario, se mantenía en una situación ambigua, debido a la falta de un reglamento propio, adecuado a sus características. Aunque formalmente seguía el modelo de Salamanca (con la variación de las diversas reformas de sus constituciones), por ser de fundación real estaba sometida a la dependencia de las autoridades virreinales, y no sólo por su régimen legal, sino porque también económicamente dependía del gobierno. En contraste, Salamanca fue desde su origen una corporación de maestros y estudiantes, con autonomía y responsabilidad de elaborar y hacer cumplir sus propios estatutos. Si México hubiera seguido fielmente ese modelo, los estudiantes deberían haber tenido la misma capacidad de decisión, pero no era así, debido a su inevitable sumisión a la autoridad virreinal. A ello se añadía el poder de las congregaciones religiosas, que dominaron durante los primeros años la vida académica de la universidad novohispana. La solución provisional fue incorporar a los oidores como doctores para que decidieran con pleno derecho en el claustro de doctores, además de que durante los primeros años hicieron recaer la elección de rector sobre un oidor. El oidor más antiguo sería, además, decano de su facultad. Con todo esto se consiguió temporalmente mantener el control 
en los miembros de la Audiencia, aunque formalmente los estudiantes podían opinar y participar como consiliarios. El claustro de consiliarios logró influir en las elecciones de catedráticos y rector durante los primeros tiempos, pero poco a poco mermaron sus funciones. Por momentos parecía que dominaban los agustinos, aunque enseguida se imponían los dominicos, para después ceder ante los seglares representantes de la Audiencia, mientras el claustro renunciaba a algunas de sus funciones. Durante casi cien años, desde su fundación, se vivió en esa incertidumbre, ya que los estatutos del oidor Farfán no se aprobaron y tampoco los del arzobispo Moya de Contreras, que no veía con buenos ojos la injerencia de la Audiencia en el gobierno universitario. El ensayo de estatutos de Cerralvo, en 1626, no corrió con mejor suerte. ${ }^{9}$

EL PERFIL DE LOS PROTAGONISTAS

Por quanto los bachilleres Josephe de Prado con Gerónimo de Quesada, Francisco de Palacios, Juan de los Ríos, Nicolás de Castañeda, Diego García, Luis de Rosas, Juan de Castañeda, Diego de Magaña, Nicolás Méndez y Antonio de Estrada me han hecho relación están cursando en la Facultad de Medicina

Los firmantes de la carta se presentaron como bachilleres y así se les reconoció, con el respeto correspondiente a su grado académico, aunque, muy probablemente, eran jóvenes graduados en Artes que, como matriculados en la carrera de Medicina acaso habrían coincidido en algunas cátedras con el presunto mulato Pedro Ciprés. ${ }^{10}$ Ya que no se menciona entre ellos a

9 González González, “La construcción del marco legal”, pp. 24-29.

${ }^{10}$ Era frecuente que, al terminar el ciclo de Humanidades, entre los 12 y 13 años, los jóvenes se inscribiesen en Artes, para concluir alrededor de los 17 o 18. Ya como bachilleres, podían ampliar sus estudios para obtener la maestría o pasar a facultades mayores. 
ningún maestro, es lógico pensar que aspiraban a graduarse en facultades mayores, por lo que no dedicaron su tiempo a obtener la maestría en Artes; pero tampoco consideraban concluidos sus estudios, a juzgar por su referencia a la Universidad, que consideran su casa. Sin duda algunos bachilleres médicos habrían iniciado su carrera profesional en la atención de enfermos, una vez acreditados los dos años de prácticas junto a un médico reconocido. ${ }^{11}$ Por supuesto, cabe pensar que quienes ya habían comenzado a ejercer su profesión no se encontrarían entre los que firmaron. Aun sin considerar esa opción ¿podría ser representativo un grupo de once? ¿Era un momento propicio para inquietudes y protestas por motivos políticos, académicos o profesionales? ¿Qué tendrían en común y en qué se distinguían los firmantes de los compañeros estudiantes y bachilleres que no incluyeron su firma? Sin duda es necesario conocer más a unos y otros. Gracias al ejemplar trabajo realizado en el antiguo Centro de Estudios sobre la Universidad (CESU), hoy Instituto de Investigaciones sobre la Universidad y la Educación (IISUE), sabemos bastante acerca de claustros y cátedras, maestros y estudiantes. Podemos conocer el proceso de consolidación de los estudios y la presencia de graduados en fechas cercanas a la que se consigna en la carta. ${ }^{12}$

De los once firmantes, al menos ocho obtuvieron en fechas próximas el grado de bachiller. Entre los que encabezan la lista: José de Prado, que lo obtuvo por pobre, sin pago de propinas, un año antes, en julio de 1633, y Juan de los Ríos poco antes de la carta, en mayo de $1634 .{ }^{13}$ Pese a haberse graduado como bachilleres, es probable que siguieran adscritos ya como aspirantes

11 LAnning, El Protomedicato, p. 472.

12 Debo un reconocimiento especial a la doctora Leticia Pérez Puente, quien me facilitó las tablas inéditas de los volúmenes de grados de bachiller, licenciado y doctor en el siglo XVII.

13 José de Prado (07/09/1633) y Juan de los Ríos (26/05/1634). AGN, Universidad, vol. 290, ff. 45 y 53v., respectivamente. 
a los grados de licenciado y doctor, los cuales obtuvo José de Prado una vez cumplidos los cuatro años de prácticas como repetidor o sustituto de algún catedrático, en 1639.14 No he localizado los grados superiores de Juan de los Ríos. También fueron bachilleres Gerónimo Quesada (en 19 de diciembre de 1635), Nicolás Castañeda (en 12 de diciembre de 1635), Diego de Magaña (13 de diciembre de 1635 y posteriormente licenciado y doctor en 7 de mayo y 29 del mismo mes de 1640). Nicolás Méndez, con la exención gastos por pobre (en 5 de mayo de 1640), Diego García (21 de febrero de 1637) y Juan de Castañeda (en 6 de junio de 1636). ${ }^{15}$ Puedo suponer que los tres faltantes (Francisco Palacios, Antonio de Estrada y Luis de Rosas) también se graduaron, aunque no he encontrado sus datos. No hay duda de que todos aspiraban a graduarse como médicos y que durante los cuatro años de sus estudios habían tenido alguna comunicación con Pedro Ciprés.

A juzgar por las fechas de su graduación, quienes frecuentaban la facultad de Medicina como aspirantes al grado de bachiller y pudieron tener relación en las aulas con Pedro Ciprés correspondían a los veteranos de las promociones anteriores, desde 1630 (con graduación en el 34) hasta los recién llegados, que se graduarían en 1638 o 1639. También pudieron tratarlo los bachilleres practicantes ya como médicos, en busca del grado de licenciado y doctor. Con alguna aproximación, a partir de los libros de grado revisados, puedo calcular que en la década considerada el número de cursantes fue de 97 que se graduaron como bachilleres y 32 licenciados con los dos títulos de licenciados y doctores, o al menos con el primero. ${ }^{16}$ Siempre con

${ }^{14}$ Las fechas de ambos títulos: 27/01/1639 y 13/02/1639. AGN, Universidad, vol. 284, ff. 621-631.

${ }^{15}$ El registro de sus grados, en AGN, Universidad, en los vols. 279 (ff. 211224, 292-300), 284 (ff. 632-643) y 290 (ff. 1-10, 61-61v., 67v., 71, 211-224).

${ }^{16}$ El grado de licenciado tenía categoría académica y requería acreditar las "repeticiones" como clases impartidas en la Universidad durante cuatro años 
la reserva de que no hay certeza de que no hubiera más graduados, las cifras seguras (con la suma de 97 más 32) advierten que los quejosos eran escasamente $10 \%$ de los estudiantes matriculados en el periodo. Quizá nadie preguntó al $90 \%$ restante si firmarían junto a sus compañeros, pero no hay nada que nos sugiera que su actitud estaba a favor o en contra.

Aunque su mundo fuera, en apariencia, el mismo del virrey, no lo veían, ni podrían haberlo visto, de la misma manera, porque ellos miraban hacia su porvenir en su propia tierra, buscaban destacar en su profesión y, como tantos criollos de su generación, vislumbraban el peligro de perder el prestigio de que gozaban por el simple hecho de ser hijos, nietos o remotos descendientes de españoles.

\section{LA UNIVERSIDAD, SU HONOR Y SU DEFENSA}

[... y deseando que la honra y nobleza tan antigua de la Universidad de esta ciudad se conserve en el Augmento que le deben acudiendo a la obligación que tienen como hijos de ella [...]

Con menos de un siglo de vida, dependiente de los siempre exiguos fondos proporcionados para su mantenimiento, la Universidad de México contaba con un importante número de maestros y doctores en Artes y Teología, bastantes licenciados en Cánones, algunos en Leyes y pocos, proporcionalmente muy pocos, en Medicina. Durante las primeras décadas desde su fundación, la Universidad otorgó grados de licenciado y doctor a médicos que acreditaban sus estudios en universidades españolas y sólo realizaban el trámite de incorporación para obtener

posteriores a la obtención del bachillerato. El doctorado honorífico se complementaba con un suntuoso festejo de carácter social, que acompañaba a la licenciatura, sin requisitos académicos. Los grados durante los años 1632 a 1642 sumaron 129. AGN, Universidad, vols. 189, 191, 279, 281, 284, 285, 289, 290 y 291. 
el título que les permitía ejercer su profesión en el virreinato. La facultad de Medicina de la Real Universidad contaba con la cátedra de Prima desde 1578 y la de Vísperas desde 1598. Con estas dos cátedras, ya hay constancia de que la Real Universidad expidió títulos de bachiller al menos desde 1607. En las mismas circunstancias se encontraban algunas universidades españolas, pero las deficiencias en la enseñanza debieron ser tan notorias que el rey intervino directamente en el asunto al dictar, en 1520 , una real pragmática en que advertía que con esos títulos insuficientes, los graduados "se ivan a curar sin tener licencia ni experiencia”, por lo cual prohibía otorgar grados de bachiller en medicina en universidades que no impartieran los cuatro cursos completos. ${ }^{17} \mathrm{Al}$ recibirse en México la orden real, se abrió un tercer curso, de cirugía y anatomía, con lo que se legitimaban plenamente los grados. El cambio contribuía a impulsar los estudios, que adquirían mayor prestigio. ${ }^{18}$

En el alegato de los estudiantes puede destacarse la idea de que su facultad estaba en su apogeo por tener mayor número de alumnos matriculados o graduados que en años anteriores. La revisión de los libros de grados de los que tengo noticia me permite asegurar el número mínimo de estudiantes, pero no el máximo, que podría aumentar con registros dispersos en otros volúmenes en los que pudiera haber alguna información complementaria, pero la información disponible permite advertir que en las tres décadas inmediatas el número de bachilleres y licenciados había oscilado entre los 44 licenciados y doctores de 1607 a 1630 y los 97 considerados en la década de 1633 a 1642. De tres estudiantes por año, en promedio, se pasó a casi

17 El texto de la pragmática se reprodujo parcialmente en los estatutos de Cerralvo, edición de Enrique González, Proyecto de estatutos, p. 33.

18 Tanck de Estrada, "La Colonia”, en Arce Gurza et al., Historia de las profesiones, p. 37. 
diez. ${ }^{19}$ Como una posible explicación del incremento en el número de graduados, he señalado las consecuencias de la gran inundación, que trastocó la vida de la capital y puso en primer plano la fragilidad de los recursos para prevenir enfermedades, contagios y epidemias. Si la salud era tan vulnerable, correspondía a los médicos desempeñar una función imprescindible. Unido esto a la instalación de la tercera cátedra en la facultad de Medicina, atrajo a más estudiantes.

Tampoco puede olvidarse que el Tribunal del Protomedicato funcionaba en la Nueva España, como en todas las provincias del imperio español, y que tenía estrecha relación con la Universidad. ${ }^{20}$ Desde fecha temprana, el Ayuntamiento fue responsable de regular todo lo relacionado con la salud pública, y desde 1536 se arrogó el derecho de nombrar protomédicos, uno o dos, en distintos años y con salario de un marco de oro anual, que se repartiría entre los designados. Ya con las tres cátedras de Medicina, con las que la facultad consolidaba su prestigio, en 1628, se fundó el Tribunal del Protomedicato, que lo compondrían el catedrático de Prima de Medicina, el doctor más antiguo del claustro universitario y un médico designado por el virrey. ${ }^{21}$

\section{LOS ESTUDIANTES INFORMAN}

[...] an procurado por diferentes caminos y modos estorvar que Pedro cipres entre a cursar dicha facultad de medicina, por ser mulato y entienden no lo conseguirán por ser favorecido de personas

${ }^{19}$ Una vez más, mis referencias proceden de los datos cuyo acceso me ha facilitado Leticia Pérez Puente sobre grados registrados en AGN, Universidad, vols. 189, 191, 279, 281, 284, 285, 289, 290, 291.

20 Aguirre Beltrán y Moreno de los Arcos (coords.), Medicina novohispana; Lanning, Academic Culture.

${ }^{21}$ En 1537 se publicó el arancel de medicinas, y en 1540 se redujeron los precios. En 1540 se hizo un censo de médicos y cirujanos. En 1548 y 1549 se impuso el control del oficio de los barberos, que también tenían que sujetarse a tarifa y someterse a examen. Ávila Hernández, “Antecedentes”, pp. 257-259. 
superiores que lo amparan y fomentan y que assi ocurren ante mi para que en nombre de su majestad, como patrón de dicha real Universidad, mande que el dicho Pedro Ciprez no sea admitido a cursar dicha facultad

Está claro que la pretensión de expulsar a Ciprés no era reciente, sino que ya había motivado anteriores intentos de hacerlo salir de la facultad. En la carta no se explican los diferentes "caminos y modos" utilizados, pero no es dudoso que se trataría de oponerle cuantos obstáculos estuvieran al alcance de sus compañeros, al parecer influyentes y sin duda engreídos: humillarlo en el trato cotidiano, dificultarle el acceso a libros o mamotretos que pudieran ayudarle en el estudio, promover acusaciones contra él y menospreciar cualquiera de sus logros o aciertos. Acaso hubieran llegado a la violencia física, pero eso es algo que, obviamente, no se menciona. Se destaca, por el contrario, la protección de que gozaba, según suponían, por parte de autoridades o "personas superiores". Ya fueran civiles o eclesiásticos, académicos o burócratas, lo que se aprecia es que no faltaban en la capital del virreinato quienes alentaban a los mulatos y otros miembros de las castas a superar su condición y estimular la agudeza de su talento y la variedad de sus dotes naturales mediante el estudio o la práctica de artes y oficios.

En ese terreno, la carta es un ejemplo que ilustra la forma en que una minoría criolla aspiraba a proteger sus privilegios frente a los grupos más humillados y desprotegidos. Con ancestros indudablemente esclavos y acaso parientes en viviendas modestas y con trabajos miserables, el esfuerzo de los mulatos para escalar posiciones respetables era muy superior al que se exigía a los acomodados descendientes de vecinos españoles. La mirada del historiador del siglo xxI puede reconocer que el camino hacia la igualdad de oportunidades no tuvo fácil el tránsito del oscurantismo, el rechazo y la segregación hacia una sociedad progresista y humanitaria, impulsada por los vientos 
de la modernidad liberadora, sino que hubo altibajos y momentos contrastantes en que parecían compatibles la brutal aceptación de la esclavitud y la posibilidad de un ascenso social por méritos personales. Una vez obtenida la libertad, los antiguos esclavos y sus descendientes podían aspirar al libre acceso al saber, dependiente de la inteligencia y capacidad de estudio, no del color. La actitud rebelde de jóvenes que consideraban laxo el reglamento vigente estaba lejos de ser expresión de esa generosidad liberadora que se atribuye a las nuevas generaciones y, por el contrario, daba muestra de intransigencia opresiva. Su razonamiento parecía justificar el miedo de los poderosos a perder sus privilegios y la expresión con frecuencia repetida “Hasta dónde vamos a llegar!”

\section{¿UN MUNDO DE COLORES?}

[...] por no haber razón alguna para que se admita pues no ay falta de cursantes pues nunca a avido tantos como al presente y que aunque no ay estatuto que lo probiva fue porque no pudo presumir semejante caso que a prevenirlo lo biciera y como lo bacen muchas de las Artes mecánicas por los inconvenientes grandes que se siguen que semejantes personas las quieran exercitar.

Es oportuno señalar la incongruencia en la respuesta de Cerralvo, que rechazaba la petición, pero en cierto modo coincidía con la demanda al declarar, en su resolución del caso, que, si se llegasen a aprobar los estatutos redactados por él, se incorporaría alguna cláusula de exclusión. Ya que el estudio de los estatutos se inició poco después de su llegada, en 1624, bien podría suceder que hubiera cambiado de parecer, cuando sugiere que su reglamento sería diferente, si tuviera la oportunidad de publicarlo y hacerlo cumplir. Esto lo dice pese a que ya había aprobado el proyecto que conocemos, que fue enviado a la corte para su aprobación en 1626, en el cual nada se menciona sobre 
impedimentos para graduarse o matricularse por consideraciones de diferencias de calidad. ${ }^{22}$ Nada semejante podría oponerse a los indios, que tenían pleno derecho a ingresar en la Real Universidad. Así constaba en la cédula fundacional de estudios generales para "los hijos de los naturales y de los españoles". ${ }^{23}$ La aparente magnanimidad de la incondicional aceptación de los naturales en la legislación universitaria, que no se modificó, no fue suficiente para atraer a muchos estudiantes indios, que tenían vedado el acceso a un destino destacado en el sacerdocio o la burocracia. Nunca fueron muchos los indios en las aulas, si bien estudios recientes muestran que hubo algunos, en proporción muy inferior a los españoles, pero presentes y en general no identificados porque durante los primeros años ni siquiera se registraba su calidad. Siendo caciques o miembros de la nobleza, e incluso con apellidos españoles, no era necesario anotar su calidad. Años más tarde, a medida que los libros de grados y matriculas detallaban la información, comenzaron a registrarse, con frecuencia relacionados con el sacerdocio como meta. ${ }^{24}$

La sociedad novohispana presentaba un mosaico de orígenes diversos, de culturas contrastantes y de apego a creencias, tradiciones y prejuicios difíciles de armonizar. Por más que en la vieja España se hubiera dado una considerable mezcla de grupos dominantes y dominados, belicosos y pacíficos, inmigrantes arrastrados por las corrientes de violencia, o refugiados a causa de diferencias religiosas, de presuntos caballeros y modestos artesanos, nada era comparable al nivel de diversidad de la población novohispana y a los alardes de superioridad de los grupos de origen español o que presumían de tenerlo. Por otra

${ }^{22}$ González González, Proyecto de estatutos, pásim.

${ }^{23}$ Real cédula, numerosas veces citada, que ya se mencionó en Gonzalbo Aizpuru, Historia de la educación, p. 111; Menegus y Aguirre, Los indios, p. 55. El texto original fue publicado por Méndez Arceo, La Real y Pontificia, p. 122.

${ }^{24}$ Menegus y Aguirre, Los indios, pp. 65-101. 
parte, sería demasiado fácil y sin duda superficial referirse a la sociedad de castas, que con tanto éxito se ha defendido en el mundo académico. La palabra castas, que se usó (con un diferente contenido) en los libros parroquiales, y que la pintura del siglo XVIII popularizó, no tiene ninguna relación con el concepto de casta que hoy asumimos. En los registros sacramentales se aprecian errores, vacilaciones, dudas y continuos cambios en las anotaciones de la calidad de los fieles; en las ordenanzas gremiales son una minoría las que intentan rechazar a determinados grupos, al mismo tiempo que reconocen la imposibilidad de hacer efectivas las prohibiciones; los matrimonios interétnicos eran comunes y los párrocos acostumbraban unificar a todos los miembros de la familia en la calidad del jefe y, casi siempre, con tendencia ascendente. Entre los pobladores de las ciudades era común el mestizaje, con la peculiaridad de que la categoría de mestizo sólo se utilizaba provisionalmente, como escalón de acceso de indio o mulato a castizo, morisco o español. Una persona "decente", con oficio o profesión reconocido, familia honorable y buenas costumbres, "era tenido" por español. ${ }^{25}$

$Y$ que con mayor razón se debe hacer en dicha Real Universidad tan lucida y noble donde cursan hijos de hombres principales y de admitirse el dicho Pedro Cipres se seguirá que otros mulatos, dexando sus oficios quieran estudiar para llegar a valer por este camino. Pidiendome mande que ni el dicho mulato ni otro mulato alguno sea admitido a cursar dicha facultad

La carta no pone en duda la capacidad de los mulatos. Más bien insinúa que podrían estudiar y aspirar a ocupar el mismo lugar que por el momento disfrutaban en exclusiva los españoles.

25 He tratado ampliamente el tema del mestizaje y las castas en mis libros recientes: Alberro y Gonzalbo Aizpuru, La sociedad novohispana; Gonzalво Aizpuru, Los muros invisibles y Del barrio a la capital. Otras obras sobre el tema abundan en la misma teoría, como Croguennec, Societé minière. 
Lo que planteaban como problema era, en sentido inverso, que los oficios humildes quedarían abandonados o tendrían que desempeñarlos los que ahora presumían de nobleza y señorío. Una vez que los africanos habían sido arrancados de su tierra y trasladados con el fin de hacerlos trabajar según la conveniencia de los que se habían convertido en sus dueños, nadie dudaba de que a su descendencia le correspondía mantenerse sometidos a la misma servidumbre. Pero la realidad se imponía y mostraba lo contrario: no todos los hijos y nietos de esclavos seguían siéndolo, muchos ganaban, con su ingenio y habilidad, lo suficiente para comprar su manumisión, otros la recibían gratuitamente y cada día eran más numerosos los mulatos y moriscos libres que desempeñaban diferentes oficios. Esos artesanos libres eran los que comenzaban a tener mayores aspiraciones.

Es cierto que algunas ordenanzas de artesanos limitaban el acceso de los negros y mulatos a la categoría de maestro, como también lo es que no faltaban quienes, pese a todo, lo lograban, e incluso, es razonable pensar que fue su competencia lo que provocó la inclusión de tales prohibiciones. Los censos de trabajadores en los últimos años del siglo XVIII y comienzos del XIX muestran la presencia de trabajadores con ancestros africanos y, por tanto, esclavos. Amoladores, toneleros, relojeros, pasamaneros y hasta hiladores de seda y herreros, que eran oficios muy respetados, contaban con aprendices, oficiales y maestros de todas las calidades. ${ }^{26}$ En el distinguido gremio de pintores ninguno fue tan notorio como Juan Correa, quien, como maestro y veedor del gremio, firmaba sus documentos como mulato. También como mulato firmaba Tomás de Sosa, a diferencia de José de Ibarra, cuya calidad de "sangre mezclada" todos conocían, pero firmaba como español. Miguel Cabrera y José Alcíbar, pertenecientes también al grupo de los más reconocidos, tuvieron un origen dudoso, que podría identificarlos como moriscos (un

26 CAStro Gutiérrez, La extinción, pp. 158-164. 
grado apenas más cercano a español). ${ }^{27}$ Sin duda entre oficiales y aprendices, en oficios de cualquier categoría, en cuyas obras no aparecen firmas, se encontrarían igualmente mulatos y moriscos.

Para la sociedad novohispana, el destino más honroso y venerado era el sacerdocio y, al parecer, ya se habían integrado a sus filas algunos descendientes de africanos. El ejemplo más notorio, en su momento escandaloso, pero en definitiva exitoso, fue el del obispo Nicolás del Puerto, sin duda de "sangre mezclada", calificado en ocasiones de indio, pero quien por declaraciones de contemporáneos y por la descripción de sus rasgos físicos se identificaba como mulato, según demuestran estudios recientes. ${ }^{28}$ Por los mismos años en que Pedro Ciprés defendía su derecho a ser médico, este interesante personaje ya debía asistir a la facultad de Teología, la más prestigiada de la Real Universidad, donde iniciaba la que sería una brillante y conflictiva carrera académica y eclesiástica. No hay duda de que uno y otro formaban parte de una minoría, pero no eran los únicos, como lo reconocería el rector al informar al virrey.

\section{EL INFORME DEL RECTOR}

Excmo Sr. No ay estatuto en esta Real Universidad en que se funde la pretensión de los que piden que el Sr. Pedro Ciprés no sea admitido a cursar la facultad de Medicina aun en caso que sea cierto lo que proponen ya que no ay prohibición aun para los grados mayores de Licenciado y Doctor y lo que no se halla prohibido se entiende debe estar permitido y en esta conformidad an sido admitidos en esta Real Universidad a los dichos grados mayores personas en quienes con mas notoriedad han concurrido causas semejantes y a cursar y a grados menores an sido indistintamente admitidos todos y no es de más calidad la facultad de Medicina que la de Artes, en la

27 Referencias de Sánchez Reyes, “Los mulatos en el gremio”, pp. 13-16.

28 PÉrez Puente, “La sangre afrentada”, pp. 279-289. 
que el dicho Pedro Cipres está graduado de Bachiller por suficiencia en esta Real Universidad y con opinión de virtud y abilidad y tiene buena persona y aspecto por el que no manifiesta el defecto que se le opone ni consta de él por otra bía. Vuestra Excelencia en todo mandará lo que mas convenga

En 1634 era rector de la Universidad el doctor Diego de Porras Villerías, que ocupaba por segunda vez el cargo. Eran tiempos de un delicado equilibrio entre las aspiraciones de autonomía de la Universidad y las instrucciones de los virreyes, que no cejaban en su empeño de controlar el gobierno universitario. Porras Villerías se había graduado como bachiller en Teología en 1599, y como doctor en Leyes en 1609. Durante su rectorado, era también abogado de la Real Audiencia y, como cabía esperar de su formación y trayectoria, limitó su informe a razones legales, si bien no dejó de añadir su opinión, favorable en todos los terrenos a Ciprés. La ley, cualquiera que se aplicase, ya fueran los estatutos de Salamanca, los del oidor Pedro Farfán o los del arzobispo Moya de Contreras, no contenía ninguna prohibición para que se recibiesen mulatos o estudiantes de cualquier calidad. Además, no queda duda de que el rector tenía una excelente opinión del joven contra el que se dirigía la reclamación, y acaso no le simpatizasen tanto otros, aspirantes a la licenciatura y el doctorado, en quienes "concurrían causas semejantes". Tal como lo insinuaba en su informe, rechazar a Pedro Ciprés podría ocasionar un grave desorden, al plantearse el dilema de expulsar a todos o seleccionar con algún criterio a los que saldrían y los que permanecerían cursando estudios superiores.

La mirada del rector, atento a conservar la armonía en las aulas y la legitimidad de los grados otorgados y en proceso, descansaba sobre una tradición hasta el momento respetada sin reservas. Ni siquiera mencionaba la posibilidad de un cambio en el futuro porque, con realismo propio de sus funciones, se atenía 
a aquello que había funcionado y con lo cual debía sentirse orgulloso de la institución que regía.

\section{EL VIRREY RESPONDE Y PEDRO CIPRÉS SE GRADÚA}

[...] aun quando yo resolviere hazer ordenanzas nuevas para que no sean admitidos negros ni mulatos no debe obrar en lo ya admitido sino en lo futuro y el considerado está ya matriculado y oyendo y fue admitido al curso y tampoco está verificado que padezca el dicho defecto - por el presente mando a vuestra señoría, el dicho rector y catedráticos de la dicha facultad de Medicina dexen cursarla al dicho Señor Pedro Ciprés y no le pongáis impedimentos en sus estudios.

A lo largo de cuatro años, desde marzo de 1634, Pedro Ciprés cursó las materias, que completó en junio de 1637, según las constancias que firmaron los catedráticos de Prima, Vísperas y Cirugía y se integraron a su expediente. ${ }^{29}$ Además informó que había cumplido con las diez "lecturas" o lecciones magistrales exigidas por el reglamento. No fue sencillo para él satisfacer todos los requisitos, cuando muchos de sus compañeros conseguían dispensas para librarse de los actos académicos prescritos. Un apellido noble, un pariente influyente o, entre los frailes, la pertenencia a las órdenes regulares, era suficiente para obtener dispensas de las que años más tarde se realizó un minucioso listado. El obispo, visitador y por breve tiempo virrey interino, don Juan de Palafox y Mendoza, ordenó una lista de "las irregularidades” autorizadas por el virrey y el claustro para dispensar

${ }^{29}$ El nombre de Pedro Ciprés aparece en el registro de bachilleres en Medicina elaborado por Fernández de Recas, Medicina. Nómina. Aunque las fechas no corresponden a cuatro años del calendario astronómico, los catedráticos señalaron detalladamente la duración de los cursos, más o menos largos, de modo que Ciprés comenzó sus estudios en 18 de marzo de 1634, para terminarlos en 12 de junio de 1637. AGN, Universidad, vol. 281, ff. 217-224. 
obligaciones en todas las facultades. No aparece en ella el nombre de Pedro Ciprés, en lo cual coincide con las constancias de grados que se encuentran en su expediente. No hubo permisos especiales, tolerancias ni beneficios para quien sólo pudo gozar de la dispensa otorgada por el virrey, que le autorizaba a cursar lo que el reglamento le permitía. ${ }^{30}$

$\mathrm{Al}$ parecer, Ciprés no participó en ningún incidente durante sus estudios. Es probable que necesitase el beneficio de la exención de pago de derechos, pero que no se le concediera y acaso ni siquiera la solicitara precisamente a causa del antagonismo con los miembros del grupo influyente que se enfrentó con él. No es probable que sólo su apariencia generase tal molestia a sus compañeros como para pedir su expulsión, cuando ya había obtenido el bachillerato de Artes y había completado el primer semestre en la facultad de Medicina. Tampoco parece que la protesta de los intransigentes afectase las rutinas del trato cotidiano. Al menos uno de los firmantes, Diego García de Daza, debió de mantener una relación suficientemente cordial con el mismo Ciprés, como para solicitar que lo avalase en la probanza de cursos que presentó en junio de $1635 .{ }^{31}$ Éste y otros documentos nos muestran que su apellido no era Ciprés, como quedó en la carta del virrey, ni Siprés, como aparece en las listas de los expedientes, sino Cipreses, tal como firma en las ocasiones en que respaldó a sus compañeros. Es probable que tampoco fuera el más popular entre ellos, puesto que sólo tres lo incluyeron entre quienes firmaron sus probanzas, pero tampoco fue rechazado, puesto que en esas ocasiones aparece junto a otros quince. Y, gracias precisamente a la información de los cursos, que incluye los cuatro años de su carrera académica, podemos saber que en

30 A GI, Patronato, leg. 244, ramo 14.

${ }^{31}$ Reunidas en los volúmenes identificados como "Cursos", las probanzas eran documentos que acreditaban la asistencia a los cursos correspondientes a las tres cátedras en los cuatro periodos anuales y debían estar firmadas por dos compañeros. 
total sumaron 40 los que sin duda en algún momento coincidieron con Pedro en las clases. ${ }^{32}$ La protesta que dio origen al expediente original fue firmada por 11, o sea, aproximadamente, la cuarta parte de quienes cursaban la carrera, que quizá se consideraron suficientemente influyentes o bien fracasaron en algún intento de obtener la firma de otros compañeros para dar mayor fuerza a su ataque contra el compañero incómodo. Si así fue, tropezaron con 29 que no firmaron. Y podría sugerir que el cabecilla de la protesta fue Diego Magaña, que por esas fechas ya era bachiller y seguía asistiendo a las clases en el prestigioso lugar de quien aspiraba al doctorado. Magaña aparece entre quienes acreditaron los cursos de los mismos que firmaron contra el mulato y que, al parecer, formaban un grupo respaldado por algunas afinidades ya que se firmaron unos a otros en las probanzas respectivas. ${ }^{33}$

El último requisito era el examen profesional, y todavía en este último paso, Ciprés tuvo que superar la renuencia de uno de los doctores del claustro universitario, el doctor Bartolomé Gómez del Castillo, quien, según el escribano del Protomedicato, opuso “cierta contradicción”. Aunque el expediente no especifica cuál fue el motivo del rechazo, resulta evidente cuando la solicitud de examen del estudiante fue detenida hasta que unos días más tarde volvió a presentarla, junto con el testimonio de la licencia concedida por el virrey marqués de Cerralvo. Ese documento, la carta que estoy comentando, fue decisivo, ya que finalmente "se declaró por bastante la dicha información" y se

32 AGN, Universidad, vol. 423, "Cursos de Artes, Teología y Medicina", 1634-1642. La localización de estos documentos me ha permitido reducir el cálculo original de los 97 graduados en diez años. Agradezco la eficiente ayuda de Antonio Enrique Mier Flores, quien me proporcionó las imágenes fotográficas de los expedientes.

33 En el apéndice los nombres de los cursantes y los grupos que los respaldaron. El número de éstos es variable porque no siempre se solicitaban probanzas de los cuatro cursos y con frecuencia se repetían los mismos testigos para varios años. 
procedió a formar el tribunal examinador. ${ }^{34}$ Según los estatutos, los ocho sinodales nombrados por el rector propusieron cada uno dos argumentos sobre las conclusiones de la tesis de Ciprés, a los que replicó resolviendo las dificultades propuestas por cada uno. No se conservó el texto original, pero bien puede suponerse cuál sería el tono de las preguntas cuando era obligatorio que tratasen de los aforismos de Hipócrates. Sin duda hablarían de los riesgos de la "robustez", que hoy llamaríamos obesidad, así como de los excesos de una dieta rigurosa mantenida por largo tiempo, de los trastornos del sueño y de los diferentes tratamientos prescritos para pacientes según sus edades. El resultado fue que los ocho examinadores dieron la calificación A, con lo que fue aprobado nemine discrepante y, por lo tanto, declarado hábil para el ejercicio de la medicina. A favor de quienes por un tiempo quisieron expulsar a Pedro Ciprés, vale mencionar que uno de los examinadores que lo aprobaron con excelente calificación fue Juan de los Ríos, uno de los firmantes de la carta de rechazo. ${ }^{35}$

En cinco de septiembre de 1637, Pedro Ciprés recibía su título de bachiller en Medicina, tras haber superado el examen teórico en la facultad. El día 13 del mismo mes, el nuevo bachiller realizó su examen práctico en el Hospital Real de Naturales ante los doctores designados por el protomédico, quienes también dieron su aprobación. Finalmente podemos suponer que iniciaría el ejercicio profesional sin más limitaciones que las que le imponían los escasos conocimientos de la época. Es posible que todavía tuviera que enfrentarse a prejuicios de quienes preferían tratar con un galeno de tez clara, pero cuando la salud estaba en juego no sería muy importante la apariencia del médico.

\footnotetext{
34 AGN, Universidad, vol. 281, ff. 318-327.

35 Los otros siete: Sebastián de Castro, Gonzalo Rodríguez, Alonso Fernández, Nicolás Alemán, Francisco Ramos, Pedro de Monroy y fray Tomás Cano. AGN, Universidad, vol. 281, ff. 218-219.
} 
En 1674, seis años después del inicio de la aplicación de los estatutos de Palafox, otro estudiante de Medicina, Manuel de Santa Fe, de origen filipino, "hijo de indios japones blancos" y vasallo libre de la corona, fue expulsado por considerarlo chino prieto y redactó su defensa, en la que incluyó los nombres de médicos mulatos graduados durante los últimos años, uno de ellos protomédico y sacerdote, otro doctor y, entre los bachilleres incluyó a Pedro Ciprés, convertido en ejemplo de lo que un mulato podía alcanzar. Santa Fe, como Ciprés tiempo atrás, logró decisión aprobatoria y fue readmitido. ${ }^{36}$

\section{LOS ANDAMIOS DE LA RECONSTRUCCIÓN HISTÓRICA}

Hasta aquí, un documento escueto y un incidente sin relieve parecen referirse al berrinche de unos estudiantes, con pretensiones de distinción, celosos de su compañero, quizá más brillante. Pero la lectura cuidadosa nos dice mucho más, porque he podido apuntalarla con ideas generales y conceptos aplicables al mundo que se deja entrever. Si me hubieran obligado a enunciar una hipótesis de trabajo, quizá habría propuesto que la carta expresa los sentimientos de una parte de la población, dispuesta a defender privilegios en vías de extinción. Y no me habría equivocado mucho, sólo un poco. Porque, al analizar el texto, ya con las ideas a priori de los espacios culturales, los tiempos de la historia, las jerarquías en conflicto y las relaciones sociales en un precario equilibrio, habría podido llegar a la observación de una realidad mucho más compleja de lo que aparentaba, en la que quienes aceptaban las diferencias podían rechazarlas en su fuero interno, mientras que quienes aparentaban someterse a ellas, obraban como si no existieran.

He sugerido la incongruencia en la respuesta de Cerralvo, que rechazaba la petición, pero en cierto modo coincidía con la

36 Menegus y Aguirre, Los indios, pp. 63-68. 
demanda al decir que, si llegase a presentar los estatutos redactados por él, se incluiría alguna cláusula de exclusión. Ya que el estudio de los estatutos se inició poco después de su llegada, en 1524, bien podría suceder que hubiera cambiado de parecer, cuando sugiere que su reglamento sería diferente, si tuviera la oportunidad de publicarlo y hacerlo cumplir, pese a que ya había aprobado el proyecto que conocemos, el que se remitió a España para su aprobación, y en el cual nada se menciona sobre impedimentos para graduarse o matricularse por consideraciones de diferencias de calidad. ${ }^{37}$ Esta falsedad en la decisión de Cerralvo nos facilita algunas claves para comprender la actitud de unos y otros y para confirmar mi intuición de que el incidente puede considerarse un hecho social. Durante su estancia en la ciudad de México, el marqués pudo percibir aspectos de la vida local que no se limitaban a las apariencias de gran ciudad. Del mismo modo que él lo percibió, podemos apreciarlo al reconocer que el espacio es mucho más que un territorio o un paisaje, porque abarca sentimientos, creencias, relaciones personales y prejuicios compartidos. Algo parecido reconocemos en el tiempo, que es distinto según lo percibimos como pasado o como futuro, como tiempo cósmico o tiempo personal, tiempo de rutinas y tiempo de acontecimientos.

En el mundo académico parece contrario a su esencia aceptar un criterio de selección que no se base en el conocimiento; de modo que, cuando la Real Universidad se sometió a los estatutos de Palafox, discriminatorios para descendientes de africanos, estaba renunciando a algo inherente a su razón de ser. Ninguna prueba científica y ninguna experiencia académica podían acreditar que la raza influyera en la capacidad de razonar y estudiar. Autoridades virreinales y miembros del claustro tampoco podían olvidar que la universidad se fundó para hijos de los naturales y de los españoles y que los argumentos para su

37 Proyecto de estatutos, pásim. 
creación se basaron en la necesidad de resolver los problemas de una sociedad nueva y diferente y de una población en la que las diferencias deberían soslayarse o disolverse en una legislación que permitiera una convivencia justa, conforme a la ley de Dios. Frente al rigor segregacionista de quienes hablaban de pureza racial se encontraban las "personas superiores" que protegían a Pedro Ciprés, al mismo tiempo que defendían los valores universitarios. La dedicación al estudio, el servicio al prójimo (en particular en el caso de los médicos), la tolerancia y el ejercicio permanente de la búsqueda de la verdad y de la justicia eran la meta que justificaba la educación de minorías comprometidas con el bien común. Cuando el rector elogiaba la virtud y habilidad del joven mulato, estaba manifestando lo que a su juicio podían ser cualidades propias de un estudioso y, en particular, de un futuro médico. En última instancia, no se puede reducir el problema a un choque entre buenos y malos o cultos e ignorantes, sin antes advertir que es diferente contemplar la historia en el pasado que vivirla en el presente, y no es fácil retraerse a aquel presente de 1634, en el que la consigna implícita en la protesta de "españoles primero" podía ser engañosamente patriótica y progresista.

Ya que he caminado paso a paso por los párrafos del documento, según el método más anticuado, tradicional... y efectivo, consistente en hacer las preguntas pertinentes a cada comentario, queda pendiente aclarar qué pasó con la teoría. No la he olvidado y, en realidad, es lo que ha requerido más esfuerzo a lo largo del texto. Ahora, al releerlo, la encuentro con suficiente solidez: en la Real Universidad de México (y quizá puedo generalizar al medio letrado y culto de la capital del virreinato), la idea (prejuicio) de la discriminación por origen racial no fue una decisión impuesta autoritariamente desde la metrópoli, ajena a la realidad que se vivía en las provincias de Ultramar, pero aún menos respondía a una opinión añeja y generalizada. En todas las corporaciones hubo antagonismos, prejuicios y enfrentamientos 
entre profesionales en defensa de viejos derechos más fuertes que las muestras de mérito y eficiencia. Tampoco puede achacarse a la perversidad del rey y sus asesores, con el propósito malévolo de mantener en la miseria material e intelectual a una gran parte de la población americana. Envidias, vanidades, miedos y vergüenza, alimentaron la mezquindad de españoles y criollos, sumergidos en la mediocridad de su propia ineptitud y desidia, y asustados ante la posibilidad, cada día más cercana, de descender en la consideración general, que pretendieron conservar a costa de quienes ya veían como futuros competidores. La conciencia de su propia insignificancia les inspiró el medio de obtener por privilegio lo que no podían conseguir por sus méritos. Que las consecuencias sumieran en la desgracia a miles o millones de americanos no fue planeado por maldad sino por torpeza.

La secuela, que también se desprende de la lectura del documento, es que nunca se cumplieron con rigor los requisitos de legitimidad y limpieza de sangre, en parte por descuido, pero en especial por convicción, por la tranquilidad de conciencia de quienes obedecían a su razón por encima de leyes arbitrarias. Cuando estuvieron vigentes los estatutos de Palafox, a partir del último cuarto del siglo xvir, y se exigieron probanzas de legitimidad y limpieza, la variedad y creatividad de las excusas son también dignas de algún estudio. Por parte de los aspirantes siempre hubo recursos con los que cubrir cualquier falta, y por parte de las autoridades podemos suponer cierta disposición a la tolerancia, la misma que existía en los gremios de artesanos o en la inspección de las escuelas, en las que se encontraban maestros mulatos.

Hubo tiempos en que los monarcas españoles aspiraron a promulgar leyes justas. Las intenciones no fueron suficientes, pero no faltaron súbditos honestos que obraron espontáneamente al solapar los presuntos "defectos" que por ley (y contra la justicia) se consideraban faltas o deficiencias. A la larga, se pagaría caro el abismo abierto entre la legalidad y la justicia. 
Apéndice

LOS ESTUDIANTES EN LA FACULTAD DE MEDICINA (1634-1637)

\begin{tabular}{|c|c|}
\hline 1) Los firmantes de la carta & Compañeros en los cursos \\
\hline Castañeda, Juan (Br. 1636) & Nicolás Castañeda, Diego Galindo, \\
\hline Castañeda, Nicolás (Br. 1635) & Diego García Daza, Diego Magaña \\
\hline \multicolumn{2}{|l|}{ Estrada, Antonio } \\
\hline García Daza, Diego (Br. 1637) & $\begin{array}{l}\text { Juan de Vera, Pedro Cipreses, Pedro } \\
\text { de Porras }\end{array}$ \\
\hline $\begin{array}{l}\text { Magaña, Diego (Br. 1635, } \\
\text { Dr. 1640) }\end{array}$ & $\begin{array}{l}\text { Alonso Escobar, Pedro de Porras, Juan } \\
\text { Castañeda, Nicolás Castañeda, } \\
\text { Antonio Estrada, Diego García Daza, } \\
\text { Juan de Melgarejo }\end{array}$ \\
\hline Méndez, Nicolás (Br. 1640) & $\begin{array}{l}\text { Luis Céspedes, Diego Magaña, Andrés } \\
\text { Ruano, Juan de Vera }\end{array}$ \\
\hline \multicolumn{2}{|l|}{ *Palacios, Francisco } \\
\hline \multicolumn{2}{|l|}{$\begin{array}{l}\text { Prado, Joseph (Br 1633, } \\
\text { Dr. 1639) }\end{array}$} \\
\hline Quesada, Gerónimo (Br. 1635) & Diego Magaña, Nicolás Castañeda \\
\hline Ríos, Juan (Br 1634) & $\begin{array}{l}\text { Francisco Ramos Santa Cruz, Francisco } \\
\text { Salazar, Nicolás Castañeda }\end{array}$ \\
\hline "Rosas, Luis & \\
\hline
\end{tabular}

2) Quienes no firmaron contra Ciprés

Álvares, Damián

Amarilla, Manuel

*Arias, Domingo

*Arteaga, Joseph

Ayllón, Gregorio

Bonilla, Bartolomé

Cárdenas, Lucas

Céspedes, Luis

*Castro, Gerónimo

Cipreses, Pedro
Gil de Prados, Juan de Vergara

Pedro de Porras, Juan Mesa

Miguel Ruis Franco, Nicolás de la Victoria, Pedro de Porras

Alonso Fernández, Domingo Arias, Bartolomé Zerdán, Joseph de Prado Joseph de Mata, Juan de Vergara, Joseph Martínez, Juan de Mesa Juan Melgarejo, Pedro Cipreses, Pedro de Porras, Gregorio Ayllón

Miguel Ruis Franco, Gregorio Ayllón, Pedro de Porras, Mauricio de Lozada, Gabriel Yrolo 
Apéndice

LOS ESTUDIANTES EN LA FACULTAD DE MEDICINA (continúa)

\begin{tabular}{|c|c|}
\hline Cisneros, Juan & $\begin{array}{l}\text { Pedro de Porras, Francisco Manuel } \\
\text { Rendón, Bernardino Juárez, Gil } \\
\text { de Prados }\end{array}$ \\
\hline Escobar, Alonso & $\begin{array}{l}\text { Diego Magaña, Pedro de Porras, Dionisio } \\
\text { Alvear, Miguel Ruis Franco, Diego } \\
\text { García Daza, Francisco de Vera }\end{array}$ \\
\hline \multicolumn{2}{|l|}{ *Fernández, Alonso } \\
\hline Herrera, Diego & $\begin{array}{l}\text { Nicolás Castañeda, Juan Estrada, Pedro } \\
\text { Cipreses, Miguel Ruis Franco, Gil de } \\
\text { Prados, Joseph Vergara, Nicolás Leyva }\end{array}$ \\
\hline Juárez, Bernardino & $\begin{array}{l}\text { Pedro de Porras, Nicolás Leyva, Miguel } \\
\text { Ruis Franco, Juan Cisneros, Gil de } \\
\text { Prados, Joseph Martínez, Francisco } \\
\text { Yáñez }\end{array}$ \\
\hline Leyva Zarfate, Nicolás & $\begin{array}{c}\text { Bernardino Juárez, Pedro de Porras, } \\
\text { Gabriel Yrolo, Pedro de Porras, } \\
\text { Gabriel Yrolo, Mauricio Lozada }\end{array}$ \\
\hline López Hinojosa, Francisco & $\begin{array}{l}\text { Nicolás Méndez, Juan Cisneros, Joseph } \\
\text { Martínez, Lucas Cárdenas }\end{array}$ \\
\hline Lozada, Mauricio & Juan Vera, Juan Cisneros, Pedro de Porras \\
\hline $\begin{array}{l}\text { Lucero, Luis } \\
\text { "Martínez, Joseph } \\
\text { "Mata, Joseph }\end{array}$ & Lucas Cárdenas, Joseph de Mata \\
\hline Melgarejo, Juan & $\begin{array}{l}\text { Diego García Daza, Juan Castañeda, } \\
\text { Gregorio Ayllon, Lorenzo Pinelo }\end{array}$ \\
\hline Pinelo, Lorenzo & $\begin{array}{l}\text { Luis de Céspedes, Miguel Ruis Franco, } \\
\text { Mauricio Lozada, Francisco Yáñez }\end{array}$ \\
\hline Porras, Pedro & $\begin{array}{l}\text { Miguel Ruis Franco, Juan de Vera, } \\
\text { Francisco Rendón, Nicolás de la } \\
\text { Victoria }\end{array}$ \\
\hline Prados, Gil & $\begin{array}{c}\text { Bernardino Juárez, Miguel Ruis Franco, } \\
\text { Bernardino Cisneros, Juan de Mesa }\end{array}$ \\
\hline Quiñones, Juan & $\begin{array}{l}\text { Bartolomé Bonilla, Domingo de Nava, } \\
\text { Joseph de Prado, Francisco Ramos } \\
\text { Santa Cruz }\end{array}$ \\
\hline Rendón, Francisco Manuel & Juan Melgarejo, Gregorio Ayllón, Juan \\
\hline Ruano, Andrés & $\begin{array}{l}\text { Francisco de Vera, Blas Silva, José Arteaga, } \\
\text { Gerónimo Castro }\end{array}$ \\
\hline
\end{tabular}


Apéndice

LOS ESTUDIANTES EN LA FACULTAD DE MEDICINA (concluye)

\begin{tabular}{|c|c|}
\hline Ruis Franco, Miguel & $\begin{array}{l}\text { Francisco Manuel Rendón, Pedro Orense, } \\
\text { Gil de Prados, Juan de Vergara, Joseph } \\
\text { de Mata }\end{array}$ \\
\hline Salazar, Francisco, & $\begin{array}{l}\text { Francisco Ramos Santa Cruz, Juan de los } \\
\quad \text { Ríos }\end{array}$ \\
\hline Vera, Juan & $\begin{array}{l}\text { Diego García, Mauricio de Lozada, Pedro } \\
\text { de Porras, Juan Cisneros }\end{array}$ \\
\hline Vergara, Juan & $\begin{array}{l}\text { Miguel Ruis Franco, Nicolás Tejeda, } \\
\text { Nicolás de la Victoria, Joseph de Mata }\end{array}$ \\
\hline Victoria, Nicolás & Pedro de Porras, Juan de Vera \\
\hline Yáñez, Francisco & $\begin{array}{l}\text { Damián Gastelun, Juan de Mesa, } \\
\text { Bernardino Cisneros, Joseph Martínez }\end{array}$ \\
\hline Yrolo, Gabriel & $\begin{array}{l}\text { Francisco Yáñez, Miguel Ruis, Nicolás de } \\
\text { Leyva, Gil de Prados, Joseph Martínez, } \\
\text { Damián Gastelun, Juan de Mesa }\end{array}$ \\
\hline *Zerdán, Bartolomé & \\
\hline
\end{tabular}

SIGLAS Y REFERENCIAS

AGI Archivo General de Indias, Sevilla, España.

AGN Archivo General de la Nación, Ciudad de México, México.

Aguirre Beltrán, Gonzalo y Roberto Moreno de los Arcos (coords.), Medicina novohispana. Siglo XVI, t. II de la Historia general de la medicina en México, México, Academia Nacional de Medicina, Universidad Nacional Autónoma de México, 1990.

Alberro, Solange y Pilar Gonzalbo Aizpuru, La sociedad novohispana. Estereotipos y realidades, México, El Colegio de México, 2013.

Arce Gurza, Francisco, Mílada Bazant, Anne Staples, Dorothy Tanck de Estrada y Josefina Zoraida Vázquez, Historia de las profesiones en México, México, El Colegio de México, 1982. 
Ávila Hernández, María Rosa, “Antecedentes del Tribunal del Protomedicato en la Nueva España”, en Rodríguez Pérez y Martínez Barbosa (coords.), 1990, pp. 245-260.

Castro Gutiérrez, Felipe, La extinción de la artesania gremial, México, Universidad Nacional Autónoma de México, 1986.

Croguennec, Soizic, Societé minière et monde mètis. Le centre-nord de la Nouvelle Espagne au XVIII siècle, Madrid, Casa de Velázquez, 2015.

Fernández de Recas, Guillermo S., Medicina. Nómina de bachilleres, licenciados y doctores, 1607-1780 y Guia de méritos y servicios, 1763-1828, México, Universidad Nacional Autónoma de México, 1960.

Gonzalbo Aizpuru, Pilar, Historia de la educación en la época colonial. La educación de los criollos y la vida urbana, México, El Colegio de México, 1990.

Gonzalbo Aizpuru, Pilar, Los muros invisibles. Las mujeres novohispanas y la imposible igualdad, México, El Colegio de México, 2016.

Gonzalbo Aizpuru, Pilar, Del barrio a la capital. Tlatelolco y la ciudad de México en el siglo XVIII, México, El Colegio de México, 2017.

GonZÁlez GonZÁlez, Enrique, “La construcción del marco legal”, en MARSISKE (coord.), 2001, pp. 24-29.

Lanning, John Tate, Academic Culture in the Spanish Colonies, Londres, Nueva York, Oxford University, 1940.

LANNING, John Tate, El Real Protomedicato. La reglamentación de la profesión médica en el Imperio español, México, Universidad Nacional Autónoma de México, 1997.

Marsiske, Renate (coord.), La Universidad de México. Un recorrido histórico de la época colonial al presente, México, Universidad Nacional Autónoma de México, Plaza y Valdés, 2001.

Méndez Arceo, Sergio, La Real y Pontificia Universidad de México. Antecedentes, tramitación y despacho de las reales cédulas de erección, México, Universidad Nacional Autónoma de México, 1990. 
Menegus, Margarita y Rodolfo Aguirre, Los indios, el sacerdocio y la Universidad en Nueva España. Siglos XVI-XVIII, México, Universidad Nacional Autónoma de México, Plaza y Valdés, 2006.

Pavón Romero, Armando, "La organización escolar" y "La población universitaria”, en MARSISKE (coord.), 2001, pp. 42-57 y 58-62.

Pavón Romero, Armando (coord.), Promoción universitaria en el mundo hispánico. Siglos XVI al XX, México, Universidad Nacional Autónoma de México, 2012.

Pérez Puente, Leticia, "La sangre afrentada y el círculo letrado. El obispo Nicolás del Puerto, 1619-1681”, en Pavón Romero (coord.), 2012, pp. 271292.

Proyecto de estatutos ordenados por el virrey Cerralvo (1626), La Real Universidad de México. Estudios y textos III, edición y estudio de Enrique González González, México, Universidad Nacional Autónoma de México, 1991.

Reales cédulas de la Real y Pontificia Universidad de México (1551-1816), estudio preliminar de Rafael Heliodoro Valle, México, Universidad Nacional Autónoma de México, 1946.

Rodríguez Pérez, Martha Eugenia, "La Real y Pontificia Universidad de México y las cátedras de Medicina”, en Rodríguez Pérez y Martínez BarBOSA (coord.), Medicina novohispana, 1990, pp. 261-271.

Rodríguez Pérez, Martha Eugenia y Xóchitl Martínez Barbosa (coords.), Medicina novohispana. Siglo XVI, t. II de Historia general de la medicina en México, México, Universidad Nacional Autónoma de México y Academia Nacional de Medicina, 1990.

Rodríguez-Sala, María Luisa y colaboradores, Alumnos, bachilleres y licenciados: sus redes sociales (etapa barroca, 1622-1727), México, Universidad Nacional Autónoma de México, 2014.

SÁnchez ReYes, Gabriela, "Los mulatos en el gremio de pintores novohispanos: el caso de Tomás de Sosa, ca. 1655-ca. 1712", en Boletín de Monumentos Históricos, tercera época, 13 (mayo-ago.), 2008, pp. 8-20.

Tanck de Estrada Dorothy, "La Colonia”, en Arce Gurza, Bazant, Staples, Tanck de Estrada y Vázquez, 1982, pp. 5-68. 